\title{
Transparent Cellulose/Polyhedral Oligomeric Silsesquioxane Nanocomposites with Enhanced UV-Shielding Properties
}

\author{
Ye Feng, Jinming Zhang*, Jiasong He, Jun Zhang* \\ Beijing National Laboratory for Molecular Sciences, CAS Key Laboratory of \\ Engineering Plastics, Institute of Chemistry, Chinese Academy of Sciences (CAS), \\ Beijing, 100190, China
}

\section{Abstract}

The solubility of eight types of polyhedral oligomeric silsesquioxane (POSS) derivatives in an ionic liquid 1-allyl-3-methylimidazolium chloride (AmimCl) and the dispersion of POSS in cellulose matrix were examined. Only a special POSS containing both aminophenyl and nitrophenyl groups (POSS-AN, $\mathrm{NH}_{2}: \mathrm{NO}_{2}=2: 6$ ) was selected to prepare nanocomposites, because of its good solubility in $\mathrm{AmimCl}$ and high stability during the preparation process. POSS-AN nanoparticles were uniformly dispersed in a cellulose matrix with a size of $30-40 \mathrm{~nm}$, and so the resultant cellulose/POSS-AN nanocomposite films were transparent. The mechanical properties of the films achieved a maximum tensile strength of $190 \mathrm{MPa}$ after addition of $2 \mathrm{wt} \%$ POSS-AN. Interestingly, all of the cellulose/POSS-AN films exhibited high UV-absorbing capability. For the $15 \mathrm{wt} \%$ cellulose/POSS-AN film, the transmittance of UVA (315-400 $\mathrm{nm})$ and UVB (280-315 $\mathrm{nm}$ ) was only $9.1 \%$ and nearly 0 , respectively. The UV aging

*Corresponding author.

Address: Institute of Chemistry, Chinese Academy of Sciences

Zhongguancun North First Street 2,100190 Beijing, China

Tel: +8610 62613251, Fax: +861062613251.

E-mail address: zhjm@iccas.ac.cn (JM Zhang), jzhang@iccas.ac.cn (J Zhang) 
and shielding experiments showed that the transparent cellulose/POSS-AN nanocomposite films possessed anti-UV aging and UV shielding properties.

Key words: cellulose nanocomposite; POSS; UV-shielding; anti-UV aging

\section{Introduction}

Biopolymers are non-toxic, environmentally friendly and biodegradable materials (Rinaudo, 2006; Nair \& Laurencin, 2007). Currently, there is a fast growing tendency to use biopolymers for replacing nondegradable materials, thereby reducing the environmental pollution. However, some properties of biopolymers are not good enough to meet the requirments in the real world. Incorporation of nanoparticles into particular properties of materials. Therefore, biopolymer nanocomposites, which contain the advantages of biopolymers and the functionalities of nanoparticles, have 
44 of aprotic polar solvents, ionic liquids (ILs), which can dissolve efficiently cellulose, present a new and versatile platform for cellulose chemists (Cao et al., 2009; Zhang et al., 2010; Hameed, Guo, Tay \& Kazarian, 2011). Via using ILs as solvents, many works have been done to fabricate cellulose-based composites with different kind of fillers, such as carbon nanotubes (Zhang et al., 2007), halloysite (Soheilmoghaddam \& Wahit, 2013; Soheilmoghaddam, Wahit, Mahmoudian \& Hanid, 2013; Hanid, Wahit, Guo, Mahmoodian \& Soheilmoghaddam, 2014), ZnO nanoparticles (Bagheri \& Rabieh, 2013). structure, as shown in Fig. 1A. The Si-O-Si inorganic cage structure provides high thermal stability and mechanical properties. Meanwhile, the physical and chemical properties of POSS are designable by the change of the substituted groups at one or more of the corner Si atoms (Kuo \& Chang, 2011; Paftopoulos \& Pielichowski, 2016). POSS molecules can have different inert and active groups, which make POSS molecules compatible with different polymer systems, and form composites with improved thermal and mechanical properties, flame retardant performance, low functional POSS nanofillers to form cellulose/POSS nanocomposites by using an ionic 
we tested the solubility of different POSS derivatives in the AmimCl. Then, we selected the POSS derivatives with the best solubility to observe their stability during the film preparation process. Finally, the POSS with both aminophenyl and nitrophenyl groups (POSS-AN, $\mathrm{NH}_{2}: \mathrm{NO}_{2}=2: 6$ ) was used to prepare POSS/cellulose nanocomposites. The resultant cellulose/POSS-AN nanocomposites exhibited high tensile strength of 150-190 MPa. Meanwhile, they were highly transparent in the visible light region, and exhibited strong absorbance in the UV region, resulting in good anti-UV aging and shielding properties.

\section{Materials and methods}

\subsection{Materials}

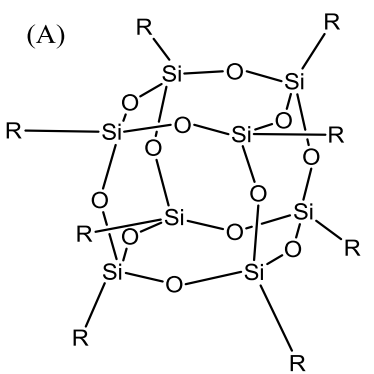

\begin{tabular}{|c|c|c|c|}
\hline Samples & $\begin{array}{l}\text { Substituted } \\
\text { groups }(\mathrm{R})\end{array}$ & Samples & $\begin{array}{l}\text { Substituted } \\
\text { groups (R) }\end{array}$ \\
\hline POSS- ${ }^{+}$ & $-\left.\mathrm{O}^{-+}\left(\mathrm{CH}_{3}\right)_{4}\right|_{8} \cdot \mathrm{xH}_{2} \mathrm{O}$ & POSS-H & $-\left.H\right|_{8}$ \\
\hline POSS-A & $-\left.\mathrm{NH}_{2}\right|_{8}$ & POSS-P & \\
\hline POSS-AN & & POSS-M & $\left.-\mathrm{CH}_{3}\right]$, \\
\hline POSS-N & & POSS-S & - $\mathrm{OSi}\left(\mathrm{CH}_{3}\right)_{3}$ \\
\hline
\end{tabular}

Fig. 1. Structure of POSS (A) and POSS derivatives (B) used in this experiment.

Various modified polyhedral oligomeric silsesquioxane (POSS) with different substituents were purchased from MeiXi Chemical Co., Ltd. (Shenyang, China). The structures of the eight types of POSS are shown in Fig. 1B. Microcrystalline cellulose (MCC) was purchased from FengLiJingQiu Co., Ltd. (Beijing, China, Vivapur 101, purity $99.5 \%$, degree of polymerisation: 220). The ionic liquid AmimCl was prepared in our laboratory according to the method described in our previous work (Zhang, Wu, 
Zhang \& He, 2005). The water content of AmimCl was below 300 ppm, which was measured by Karl-Fisher titration.

\subsection{Experimental methods}

The preparation of the cellulose/POSS nanocomposite films includes the following five steps: (a) dissolving certain amount of cellulose and POSS in AmimCl, (b) slowly pouring and spreading the solution on a glass plate, (c) placing the coated glass plate into a coagulation bath (deionised water), then forming the hydrogel, (d) washing the hydrogels with deionised water to remove the remaining $\mathrm{AmimCl}$, and (e) drying the hydrogel to obtain the dry cellulose/POSS nanocomposite films.

To prepare a uniformly dispersed nanocomposite in this system, there are two important factors that must be considered: First, in step (a), the nanoparticles must be soluble or dispersed uniformly in the $\mathrm{AmimCl}$, so that no agglomeration occurs during the precipitation. Second, during steps (c) and (d), the POSS nanoparticles must not migrate into the coagulation bath during the exchange of $\mathrm{AmimCl}$ and water. Therefore, the experiment was carried out as follows.

\subsubsection{Solubility of POSS in AmimCl}

In this step, $5 \mathrm{mg}$ of POSS was added to $10 \mathrm{~g}$ of AmimCl. The mixture was stirred for $24 \mathrm{~h}$ at room temperature, then sonicated for $10 \mathrm{~min}$. Finally, the soluble POSS derivatives were selected to test the stability during the preparation process of films.

\subsubsection{Preparation of cellulose/POSS-AN nanocomposite films}

Initially, $1 \mathrm{~g}$ of cellulose was added to $24 \mathrm{~g} \mathrm{AmimCl}$ in a three-necked flask and stirred at $80{ }^{\circ} \mathrm{C}$ for $2 \mathrm{~h}$ to completely dissolve cellulose. Then, different amount of 
POSS-AN powders were added to the cellulose/AmimCl solution. After stirring for another $4 \mathrm{~h}$ at $60{ }^{\circ} \mathrm{C}$, a vacuum was applied to remove any bubbles trapped in the solution. The solution was then coated onto a glass plate with the help of a spreader, and subsequently regenerated in a water coagulation bath. The water was periodically changed until no chloride ions could be detected by using the $\mathrm{AgNO}_{3}$ aqueous solution.

After the removal of AmimCl, a hydrogel was obtained. We dried the hydrogel to yield a series of cellulose/POSS-AN nanocomposite films containing $0,1,2,5,10,15$, and 20 wt $\%$ POSS-AN for further characterisation. The films were stored in a vacuum desiccator before tests.

\subsection{Characterisation methods}

\subsubsection{Morphology studies}

A scanning electron microscope (SEM) (JSM-6700) and a transmission electron microscope (TEM) (JEM-2200) were used to assess the morphology and dispersion of the POSS nanoparticles in the cellulose/POSS-AN nanocomposite films. For SEM observation, these films were quenched in the liquid nitrogen. Then, the cross-sections were sputter-coated with a thin layer of platinum before observation. For TEM analysis, the samples were prepared by using an ultramicrotome (UC6\&FC6, Leica) at $-60{ }^{\circ} \mathrm{C}$. The 50-100 nm thickness slice was placed onto a carbon-coated TEM grid for TEM observation in the bright field imaging mode.

\subsubsection{Tensile properties}

The tensile properties of the cellulose/POSS-AN nanocomposite films were tested by using an Instron 3365 universal testing machine with the pneumatic and serrated grip. 
Specimens with dimensions of $10 \mathrm{~mm} \times 50 \mathrm{~mm}$ were tested using a $5 \mathrm{kN}$ load cell at a strain rate of $2 \mathrm{~mm} / \mathrm{min}$. In each case, five specimens were used and the average value was reported.

\subsection{3. $U V$-vis spectra}

The films were clipped on a mold with a slit, then observed directly on the UV-vis spectrophotometer (PERSEE TU-1901). A wavelength scan mode over the range of 190 to $700 \mathrm{~nm}$ using a $1 \mathrm{~nm}$ step size was selected for this purpose.

\subsubsection{UV aging and shielding properties}

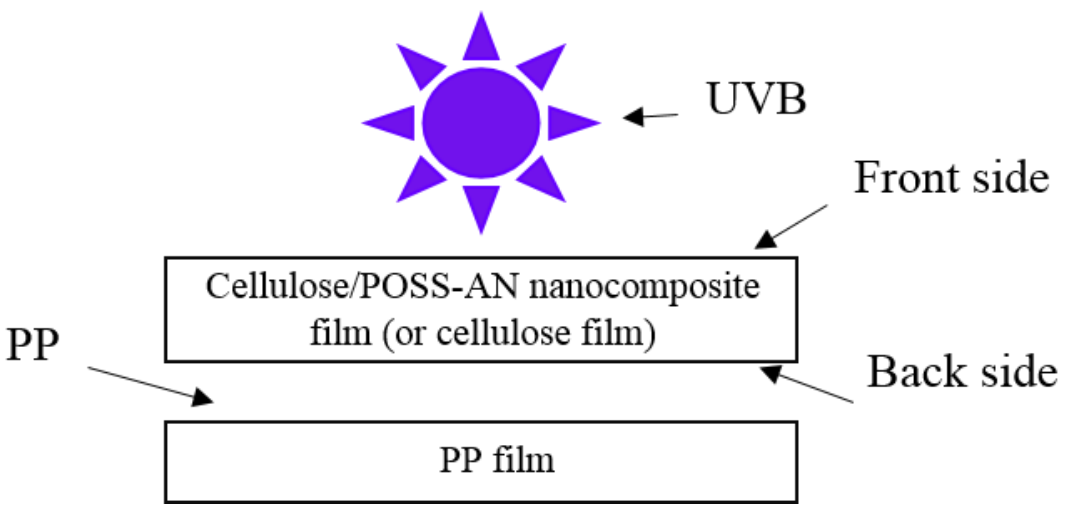

Fig. 2. UV aging and shielding testing.

As shown in Fig. 2, the UV aging and shielding test for the various cellulose/POSS-AN nanocomposite films were carried out by using UVB radiation at air atmosphere in a CL-1000 Ultraviolet Crosslinker (UVP LLC) for different periods (0-14 days). A polypropylene (PP) film was covered by a cellulose/POSS-AN nanocomposite film or a neat cellulose film. The UVB radiation source was G8T5E bulbs (Ushio) with the peak emission at $302 \mathrm{~nm}$. The composite samples were placed at a distance of $12 \mathrm{~cm}$ from the light source, corresponding to an exposure of 80,000 
$146 \mu \mathrm{J} \cdot \mathrm{cm}^{-2}$.

$147 \quad$ 2.3.5 Chemical analysis

148 The surface change in the films was characterized by using attenuated total 149 reflection-Fourier transform infrared spectroscopy (ATR-FTIR). The spectra were 150 recorded with a Nicolet 6700 FTIR spectrometer (Thermo Fisher, USA) from 650 to $1513750 \mathrm{~cm}^{-1}$ at a resolution of $4 \mathrm{~cm}^{-1}$.

152

153

154

155

156

157

158

\section{Results and discussions}

\subsection{Solubility of POSS in AmimCl}

It is well known that the good dispersion of nanofillers in the solvent and the matrix is essential to prepare nanocomposites with excellent properties (Fina, Tabuani \& Camino, 2010). The POSS nanoparticles with different substituted groups have different properties (Cordes, Lickiss \& Rataboul, 2010). So do the ionic liquids (ILs), which are composed of various cations and anions (Sun, Rodríguez, Rahmana \& Rogers, 2011). Moreover, there are many kinds of intermolecular interactions in ILs, for example, electrostatic interaction, hydrogen-bonding interaction, $\pi-\pi$ interaction, Van der Waals interaction, and so on. It is not enough to judge the dispersion of POSS in ILs by using only the polarity of POSS derivatives and ILs. Thus, the dispersion and selection of POSS derivatives had to be investigated at first.

The eight types of POSS fillers with different substituents were added into AmimCl to clarify the solubility of POSS in AmimCl. The containers of the mixtures were labelled on the basis of the substituents in the POSS fillers. As shown in Fig. 3A, it is evident that only three mixtures of AmimCl and POSS fillers marked POSS-N ${ }^{+}$, POSS-A and POSS-AN are optically clear. Other five mixtures are opaque. This phenomenon is correlated to the polarity of the substituted POSS. Because AmimCl is a 


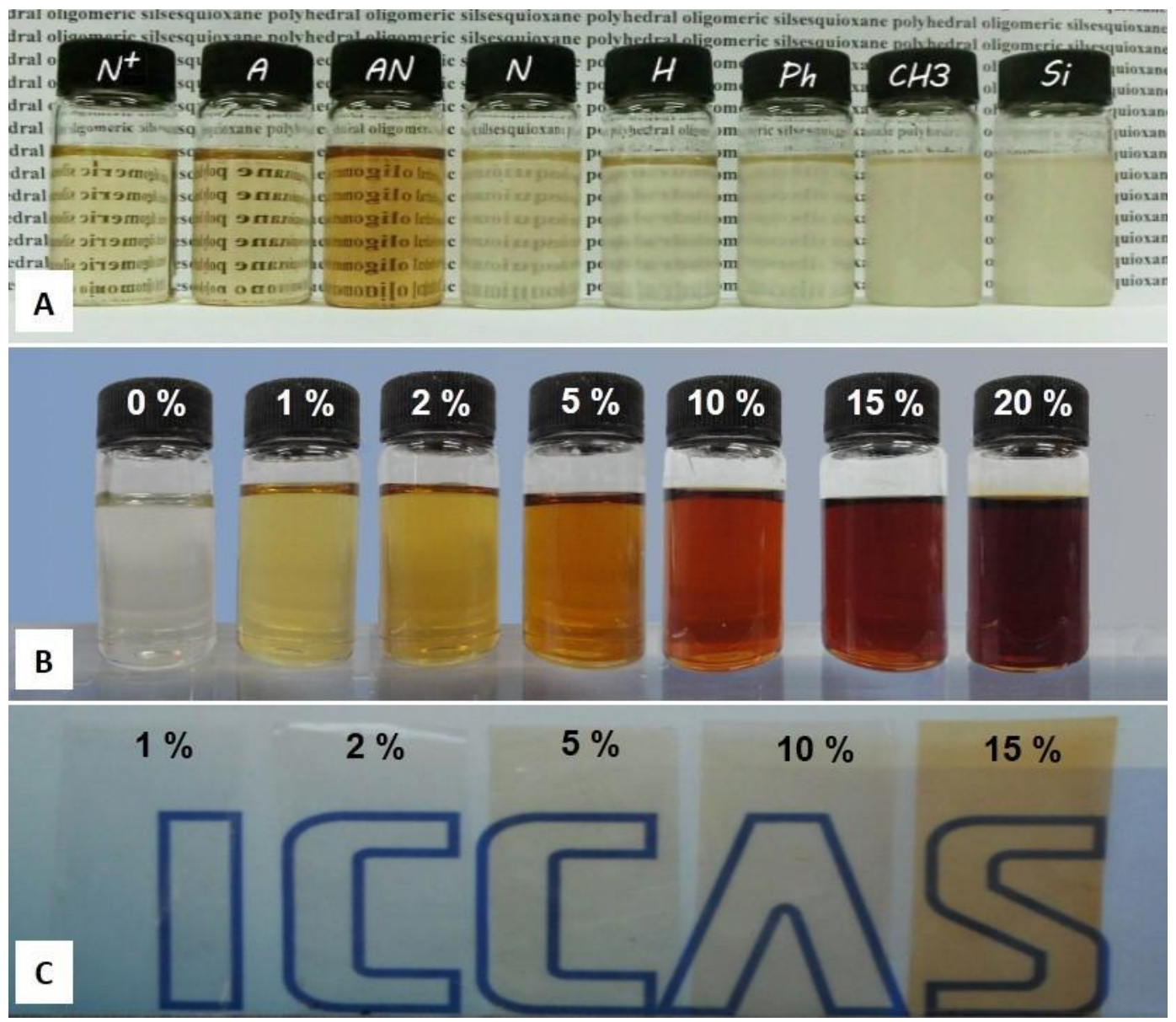

Fig. 3. Photographs of (A) POSS with different substituted groups in AmimCl, (B) cellulose/POSS-AN/AmimCl solutions ( $4 \mathrm{wt} \%$ cellulose in the solutions; $0-20 \mathrm{wt} \%$ POSS-AN referred to the total mass of cellulose and POSS), and (C) cellulose/POSS-AN nanocomposite films (1-15 wt\% POSS-AN referred to the total mass of cellulose and POSS). 
were soluble in AmimCl. Among them, we selected the POSS derivatives, which not only had a high solubility in AmimCl, but also did not migrate during the coagulation and washing processes. Because deionised water was used as the coagulation bath, the solubility of the POSS in water and $\mathrm{AmimCl} /$ water mixture is particularly important. POSS- $\mathrm{N}^{+}$was soluble in water, and POSS-A was soluble in the AmimCl/water mixture. Thus, they were washed out during the exchange process of $\mathrm{AmimCl}$ and water (steps $\mathrm{c}$ and d). Interestingly, POSS-AN with partial aminophenyl and partial nitrophenyl groups, was insoluble in both water and $\mathrm{AmimCl} /$ water. Though optical observation, UV-vis increased. All of the solutions were clear and transparent, even when the POSS-AN 

increase of the POSS-AN content made the cellulose/POSS-AN films darken, but all of the films remained transparent and homogeneous.

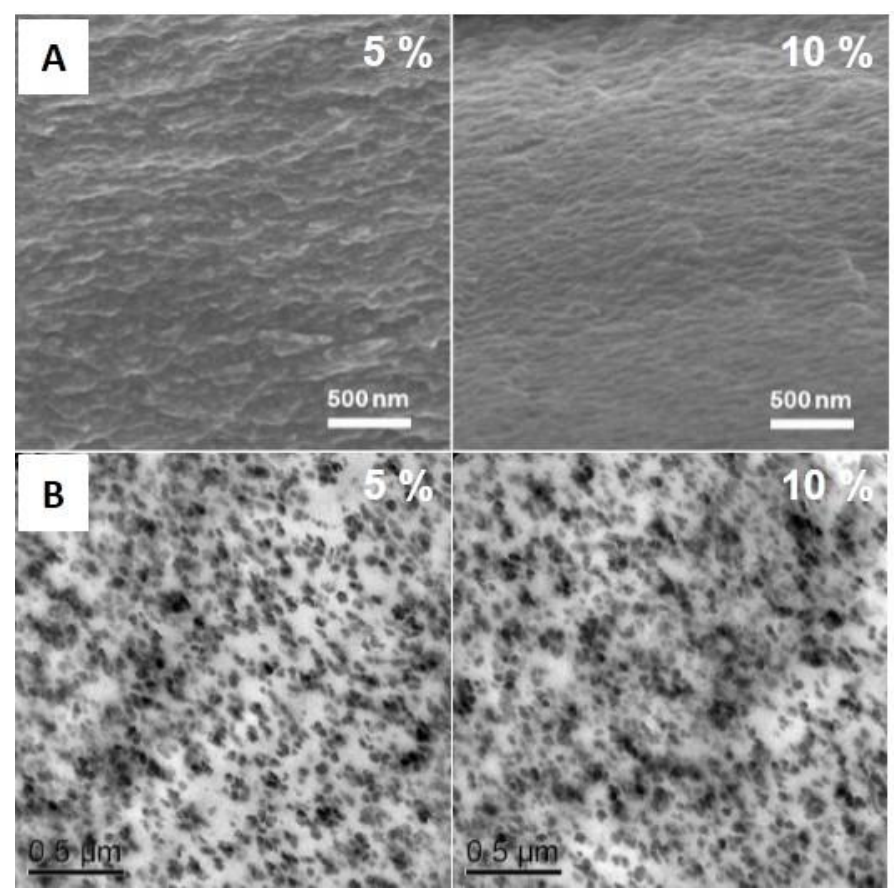

211 Fig. 4. (A) SEM photographs of the cross sections and (B) TEM photographs of two cellulose/POSS-AN nanocomposite films with $5 \mathrm{wt} \%$ and $10 \mathrm{wt} \%$ POSS-AN.

To investigate the dispersion state of POSS-AN in cellulose, SEM was used to observe the cross sections of the cellulose/POSS-AN nanocomposite films. Fig. 4A shows that the cross sections of the cellulose/POSS-AN nanocomposite films are 217 homogeneous. There are not obvious POSS-AN aggregation. Thus, the POSS-AN was well dispersed in the cellulose matrix. 
221 particles with a size of 30-40 $\mathrm{nm}$ are uniformly dispersed in the matrix. As the 222 POSS-AN content increases, the number of the nanoparticles increases. Most of nanoparticles maintain a homogeneous dispersion in the matrix. Only a small quantity of particle-aggregation appears. These results are consistent with the literature (Althues, is essential to obtain transparent nanocomposites.

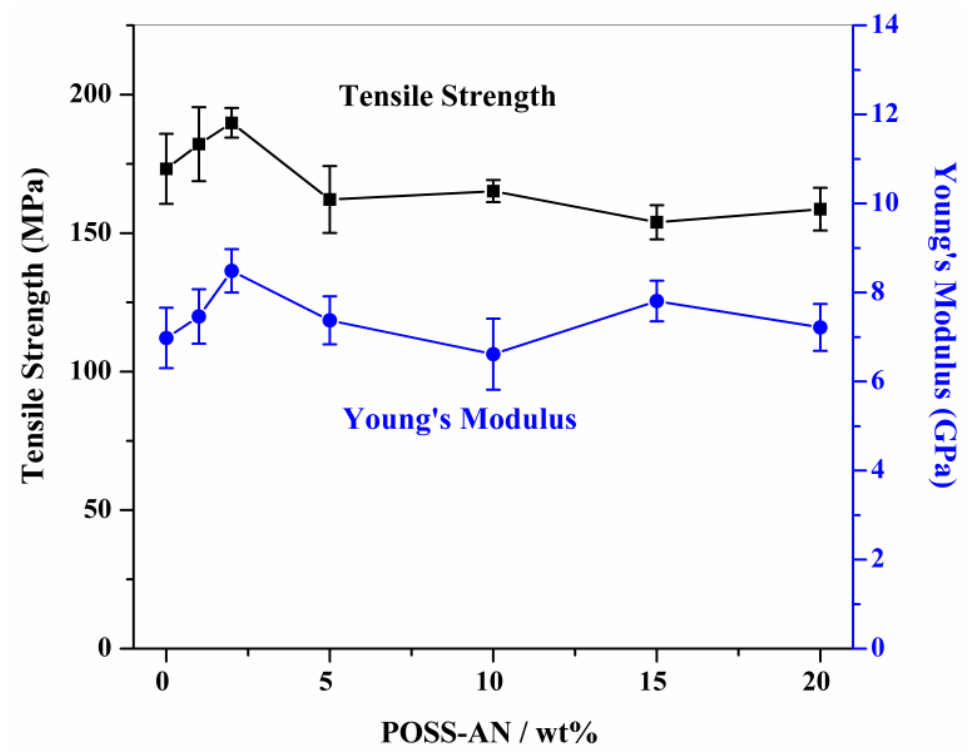

Fig. 5. The mechanical properties of cellulose/POSS-AN nanocomposite films with tensile strength and Young's modulus, are summarized in Fig. 5. As seen from the results of the tensile test, the nanocomposite films possessed good Young's modulus of 
6-9 GPa and high tensile strengths of 150-190 MPa, which were far above those of

237 conventional commercial polyolefin films, such as polyethylene (PE) and 238 polypropylene $(\mathrm{PP})$ (the tensile strength $=20-40 \mathrm{MPa}$ ). The tensile properties of the 239 cellulose/POSS-AN nanocomposites increased with the content of POSS-AN up to 2 $240 \mathrm{wt} \%$, and then fluctuated. The cellulose/POSS-AN nanocomposites film with 2 wt $\%$ 241 POSS-AN achieved a maximum tensile strength of $190 \mathrm{MPa}$. This phenomenon is 242 probably correlated to the dispersion-aggregation state of POSS-AN nanoparticles and 243 the interfacial interaction between POSS-AN and cellulose.

\subsubsection{UV-vis spectra}
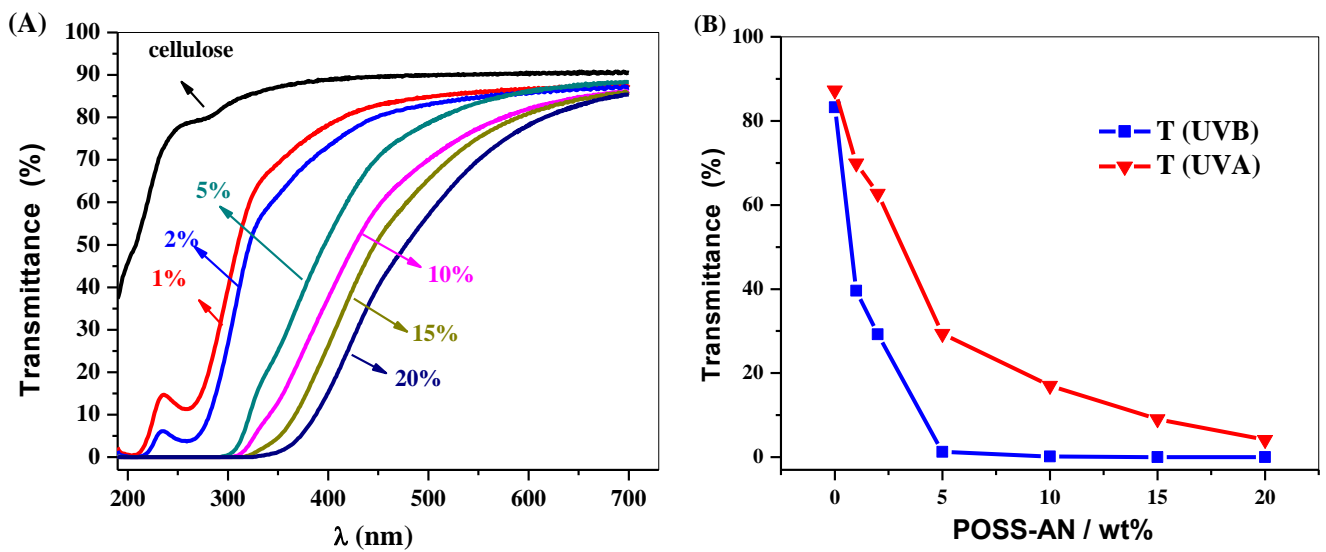

245

Fig. 6. (A) UV-vis spectra and (B) transmittance of UVA and UVB of

Fig. 6A shows the UV-vis spectra of the cellulose matrix and cellulose/POSS-AN 
dispersed in the matrix at the nanometer scale. In the UV region, absorption of neat

254

255

256

257

258

259

260

261

262

263

264

265

266

267

268

269

270

cellulose was negligible. Most of the UV was not absorbed. After adding POSS-AN, the cellulose/POSS-AN nanocomposite films showed significant absorption in the UV region, due to the existence of the chromophores (aminophenyl and nitrophenyl groups) in POSS-AN.

Fig. 6B shows the transmittance of the UVA (T (UVA)) and UVB (T (UVB)). The T (UVA) and T (UVB) can be calculated using Eqs. (1) and (2), respectively.

$$
\begin{aligned}
& \mathrm{T}(\mathrm{UVA})=\frac{\int_{315}^{400} T_{\lambda} \times d \lambda}{\int_{315}^{400} d \lambda},(1) \\
& \mathrm{T}(\mathrm{UVB})=\frac{\int_{280}^{315} T_{\lambda} \times d \lambda}{\int_{280}^{315} d \lambda},(2)
\end{aligned}
$$

where $T_{\lambda}$ is the transmittance of the light at the wavelength $\lambda$.

As shown in Fig. 6B, T (UVA) and T (UVB) decreased sharply with the increase of the POSS-AN content. After adding $5 \mathrm{wt} \%$ POSS-AN, the T (UVA) decreased from $87.3 \%$ to $29.4 \%$, and the T (UVB) decreased from $83.2 \%$ to $1.3 \%$. When the POSS-AN content reached $15 \mathrm{wt} \%$, the $\mathrm{T}$ (UVA) and $\mathrm{T}$ (UVB) decreased to $9.1 \%$ and nearly 0 , respectively. Therefore, the cellulose/POSS-AN nanocomposite films exhibit full absorption of UVB and above $90 \%$ absorption of UVA, implying that the incorporation of POSS into cellulose can effectively block UV transmission.

\subsubsection{Anti-UV aging properties}




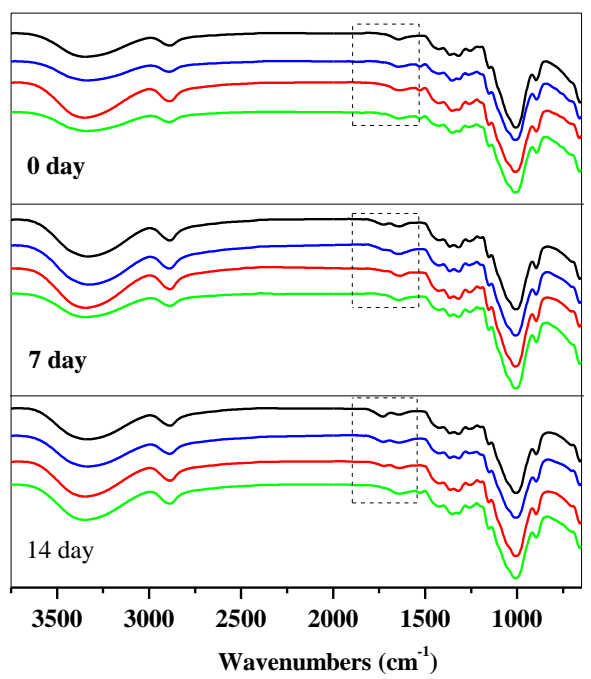

272 2004; Chen, Yang \& Zhang, 2011).

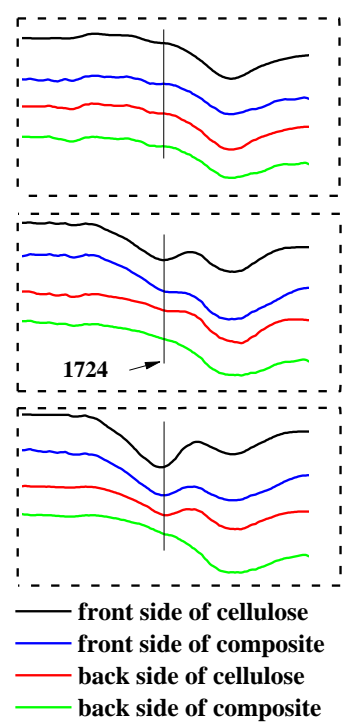

Fig. 7. FTIR spectra of neat cellulose and cellulose/POSS-AN nanocomposite (10 wt $\%$ POSS-AN) films for different UV radiation exposure time.

We used neat cellulose and cellulose/POSS-AN nanocomposite films containing 10 wt\% POSS-AN for comparison. They were exposed to UV radiation for studying their anti-UV aging properties as a function of UV radiation exposure time. The FTIR spectra of the cellulose and cellulose/POSS-AN nanocomposite films are shown in Fig. 7. The peak at $1724 \mathrm{~cm}^{-1}$ was assigned to the carbonyl group, whose intensity increased as the extension of the UV radiation exposure time. The carbonyl group was absent in the neat cellulose (Kumer, Negi, Bhardwaj \& Choudhary, 2012), so its presence in exposed cellulose indicated that some groups in cellulose was oxidized at the UV-lights irradiation, which perhaps was via a free-radical route (Seldén, Nyström \& Långström,

On the front side of cellulose film, a generated carbonyl peak appeared at 1724 
$\mathrm{cm}^{-1}$ as the UV radiation time increased. When the UV radiation time was set to 7 days, the peak was noticeable. After 14 days, the intensity of the peak increased further. However, for the cellulose/POSS-AN nanocomposite film with 10 wt\% POSS-AN, the $1724 \mathrm{~cm}^{-1}$ peak was negligible after a UV radiation exposure for 7 days. After a UV radiation exposure for 14 days, there was a clear carbonyl absorption peak. Compared to the front side of films, the peak intensity of the carbonyl group on the back side was weaker. Especially, on the back side of cellulose/POSS-AN nanocomposite films, no days. Thus, the cellulose/POSS-AN nanocomposite films exhibit good anti-UV aging property, and are expected to be used as the UV protection film.

\subsubsection{UV shielding properties}

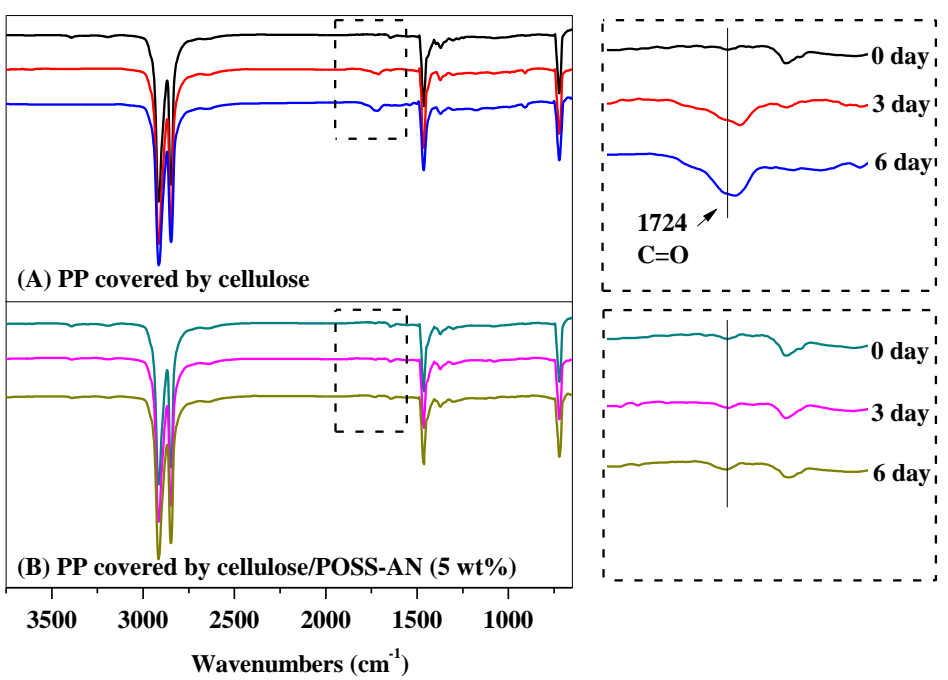

Fig. 8. FTIR spectra of PP film covered by: (A) cellulose and (B) cellulose/POSS-AN nanocomposite (5 wt\% POSS-AN) films for different UV radiation time. the cellulose and cellulose/POSS-AN nanocomposite films. We overlaid the cellulose 
film and cellulose/POSS-AN nanocomposite film (5 wt\% POSS-AN) separately on PP

304 films, then exposed them to UV radiation for 3 and 6 days. After UV radiation, the PP

305 films were separated, and their FTIR spectra (Fig. 8) were recorded. As shown in Fig.

8A, the PP covered by the neat cellulose film exhibited obvious carbonyl peaks after a 
green material and expand the application field of cellulose-based materials.

\section{Acknowledgements}

This work was supported by the National Science Foundation of China (No. 21174151, and No. 51425307).

\section{References}

Althues, H., Henle, J., \& Kaskel, S. (2007). Functional inorganic nanofillers for transparent polymers. Chemical Society Reviews, 36, 1454-1465.

Bagheri, M., \& Rabieh, S. (2013). Preparation and characterization of cellulose-ZnO nanocomposite based on ionic liquid ( [ $\left.\left.\mathrm{C}_{4} \mathrm{mim}\right] \mathrm{Cl}\right)$. Cellulose, 20, 699-705.

Cao, Y., Wu, J., Zhang, J., Li, H. Q., Zhang, Y., \& He, J. S. (2009). Room temperature ionic liquids (RTILs): A new and versatile platform for cellulose processing and derivatization. Chemical Engineering Journal, 147, 13-21.

Chen, J., Yang, M. S., \& Zhang, S. M. (2011). Immobilization of antioxidant on nanosilica and the aging resistance behavior in polypropylene. Composites: Part A 42, 471-477.

Cordes, D. B., Lickiss, P. D., \& Rataboul, F. (2010). Recent Developments in the Chemistry of Cubic Polyhedral Oligosilsesquioxanes. Chemical Reviews, 110, 2081-2173.

Darder, M., Aranda, P., \& Ruiz-Hitzky, E. (2007). Bionanocomposites: A new concept of ecological, bioinspired, and functional hybrid materials. Advanced Materials, 19, 1309-1319.

Fina, A., Tabuani, D., \& Camino, G. (2010). Polypropylene-polysilsesquioxane blends. 
European Polymer Journal, 46, 14-23.

Hameed, N., Guo, Q., Tay, F. H., \& Kazarian, S. G. (2011). Blends of cellulose and poly(3-hydroxybutyrate-co-3-hydroxyvalerate) prepared from the ionic liquid 1-butyl-3-methylimidazolium chloride. Carbohydrate Polymers, 86, 94-104.

Hameed, N., Xiong, R., Salim, N. V., \& Guo, Q. (2013). Fabrication and characterization of transparent and biodegradable cellulose/poly (vinyl alcohol) blend films using an ionic liquid. Cellulose, 20, 2517-2527.

Hanid, N. A., Wahit, M. U., Guo, Q. P., Mahmoodian, S., \& Soheilmoghaddam, M. (2014). Development of regenerated cellulose/halloysites nanocomposites via ionic liquids. Carbohydrate Polymers, 99, 91-97.

Khalil, H. P. S. A., Bhat, A. H., \& Yusra, A. F. I. (2012). Green composites from sustainable cellulose nanofibrils: A review. Carbohydrate Polymers, 87, 963-979.

Klemm, D., Heublein, B., Fink, H. P., \& Bohn, A. (2005). Cellulose: Fascinating biopolymer and sustainable raw material. Angewandte Chemie-International Edition, 44, 3358-3393.

Kueseng, K., \& Jacob, K. I. (2006). Natural rubber nanocomposites with SiC nanoparticles and carbon nanotubes. European Polymer Journal, 42, 220-227.

Kumar, A., Negi, Y. S., Bhardwaj, N. K., \& Choudhary, V. (2012). Synthesis and characterization of methylcellulose/PVA based porous composite. Carbohydrate Polymers, 88(4), 1364-1372.

Kuo, S. W., \& Chang, F. C. (2011). POSS related polymer nanocomposites. Progress in Polymer Science, 36, 1649-1696. 

silsesquioxane (POSS) polymers and copolymers: A review. Journal of Inorganic and Organometallic Polymers, 11, 123-154.

Liu, S. L., Zhang, L., Zhou, J. P., \& Wu, R. X. (2008). Structure and properties of cellulose $/ \mathrm{Fe}_{2} \mathrm{O}_{3}$ nanocomposite fibers spun via an effective pathway. Journal of Physical Chemistry C, 112, 4538-4544.

Nair, L. S., \& Laurencin, C. T. (2007). Biodegradable polymers as biomaterials. Progress in Polymer Science, 32, 762-798.

Raftopoulos, K. N., \& Pielichowski, K. (2016). Segmental dynamics in hybrid polymer/POSS nanomaterials. Progress in Polymer Science, 52, 136-187.

Rinaudo, M. (2006). Chitin and chitosan: Properties and applications. Progress in Polymer Science, 31, 603-632.

Seldén, R., Nyström, B., \& Långström, R. (2004). UV aging of poly(propylene)/wood-fiber composites. Polymer Composite, 25, 543-553.

Soheilmoghaddam, M., \& Wahit, M. U. (2013). Development of regenerated cellulose/halloysite nanotube bionanocomposite films with ionic liquid. International Journal of Biological Macromolecules, 58, 133-139.

Soheilmoghaddam, M., Wahit, M. U., Mahmoudian, S., \& Hanid, N. A. (2013).

Regenerated cellulose/halloysite nanotube nanocomposite films prepared with an ionic liquid. Materials Chemistry and Physics, 141, 936-943.

Sun, N., Rodríguez, H., Rahmana, M., \& Rogers R. D. (2011). Where are ionic liquid strategies most suited in the pursuit of chemicals and energy from lignocellulosic 
391

392

393

394

395

396

397

398

399

400

401

402

403

404

405

406

407

408

409

410

biomass? Chem. Commun., 47, 1405-1421.

Wu, J., \& Mather, P. T. (2009). POSS Polymers: Physical Properties and Biomaterials Applications. Polymer Reviews, 49, 25-63.

Zhang, H., Wang, Z. G., Zhang, Z. N., Wu, J., Zhang, J., \& He, H. S. (2007). Regenerated-cellulose/multiwalled-carbon-nanotube composite fibers with enhanced mechanical properties prepared with the ionic liquid 1-allyl-3-methylimidazolium chloride. Advanced Materials, 19, 698-704.

Zhang, H., Wu, J., Zhang, J., \& He, J. S. (2005). 1-Allyl-3-methylimidazolium chloride room temperature ionic liquid: A new and powerful nonderivatizing solvent for cellulose. Macromolecules, 38, 8272-8277.

Zhang, J. M., Zhang, H., Wu, J., Zhang, J., He, J. S., \& Xiang, J. F. (2010). NMR spectroscopic studies of cellobiose solvation in EmimAc aimed to understand the dissolution mechanism of cellulose in ionic liquids. Physical Chemistry Chemical Physics, 12, 1941-1947.

Zhang, X. M., Feng, J. X., Liu, X. Q., \& Zhu, J. (2012). Preparation and characterization of regenerated cellulose/poly (vinylidene fluoride) (PVDF) blend films. Carbohydrate Polymers, 89, 67-71.

Zhang, X. M., Liu, X. Q., Zheng, W. G., \& Zhu, J. (2012). Regenerated cellulose/graphene nanocomposite films prepared in DMAC/LiCl solution. Carbohydrate Polymers, 88, 26-30. 